\title{
The actual cost bourne by university students in Egypt: $A$ qualitative study [Arabic]
}

Population Council

Ilham Fateem

Follow this and additional works at: https://knowledgecommons.popcouncil.org/departments_sbsr-pgy

Part of the Demography, Population, and Ecology Commons, Educational Sociology Commons, and the Family, Life Course, and Society Commons How does access to this work benefit you? Let us know!

\section{Recommended Citation}

Population Council and Ilham Fateem. 2015. "The actual cost bourne by university students in Egypt: A qualitative study [in Arabic]," report. Cairo: Population Council. 


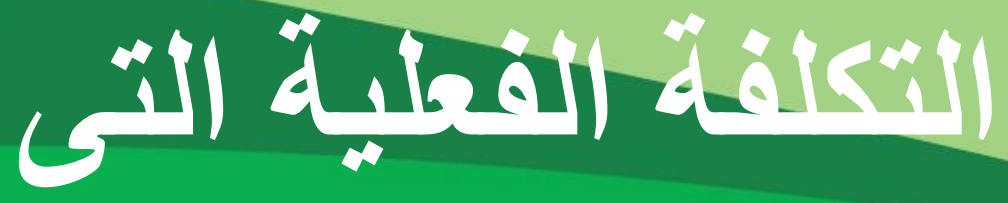

$$
\begin{aligned}
& \text { يتحملها الطالب } \\
& \text { الجامعى فى مصر التصل }
\end{aligned}
$$

2 POPULATION
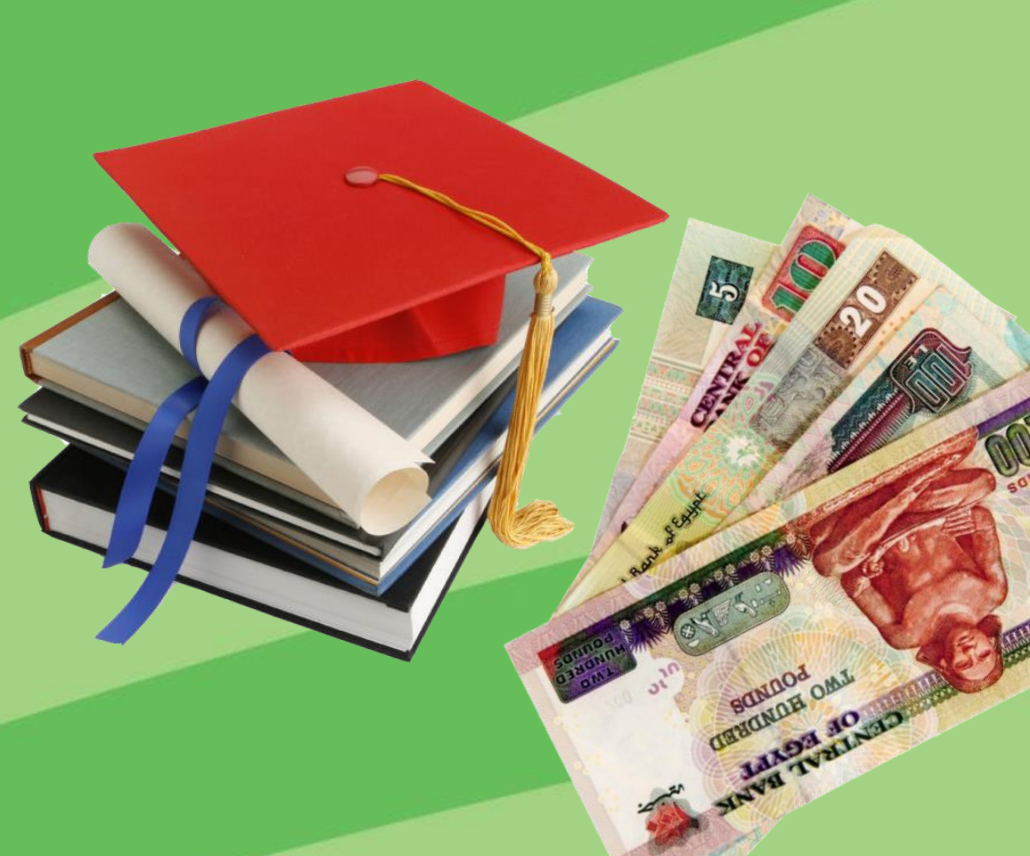
يتصدى مجلس السكان الدولي لأهم قضايا التنمية والصحة، كوقف انتشار فيروس نقص المناعة البشري،

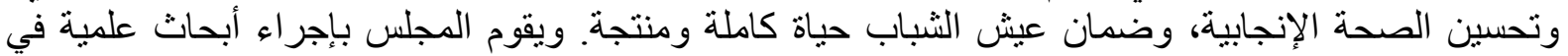

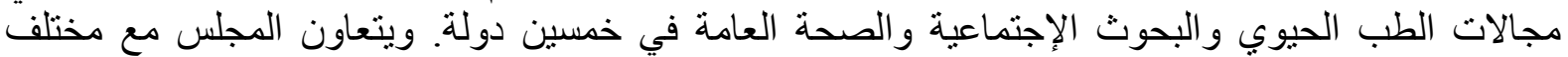

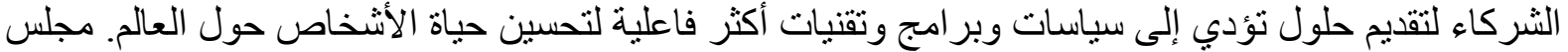

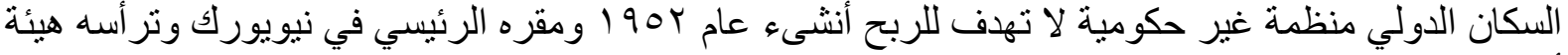

Population Council One Dag Hammarskjold Plaza

New York, NY 10017

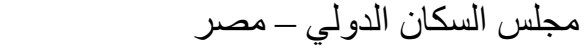

$$
\begin{aligned}
& 9 \text { ه طريق مصر حلؤ الوان الزراعي ـ المعادي } \\
& \text { صندوق بريد } 141 \text { المعادي الزي }
\end{aligned}
$$

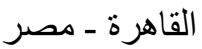

$$
\begin{aligned}
& 11 \leq \pi 1 \\
& \text { هاتف: }
\end{aligned}
$$

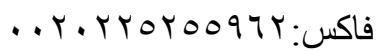

البريد الاكتروني:Info.egypt@popcouncil.org الموقع الالكتروني: www.popcouncil.org

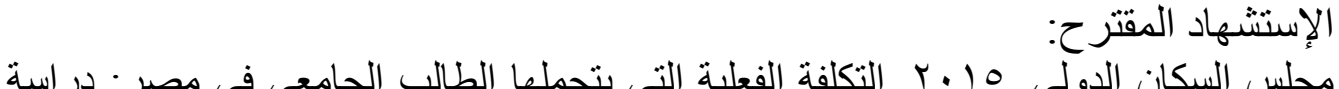
كيفية. القاهرة - مصر : مجلس السكان الدولي

\section{POPULATION}


تعد التكلفة الفعلية للتعليم الجامعى أحد أهم أسباب عزوف الطلبة والطالبات من الثرائح الاجتماعية محدودة الدخل عن الالتحاق بالتعليم الجامعى أو التى تؤدى بهم إلى اختيار كليات معينة دون غيرها تجنبا لهذه النفقات.

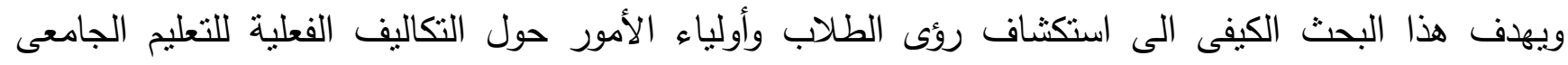
(الحكومي) والتعرف على الاستراتيجيات التى يتبعونها لمواجهة هذه التكاليف كما يهدف البحث إلى استطلاع مقترحاتهم لخفص تلك التكاليف والحد من أثزها على حياتهم وحياة أسرهم.

وقد طبق هذا البحث الكيفى بمحافظتى سوهاج والاسكندرية واحتوت عينة الدراسة على rا مجموعة نقاش بؤرية

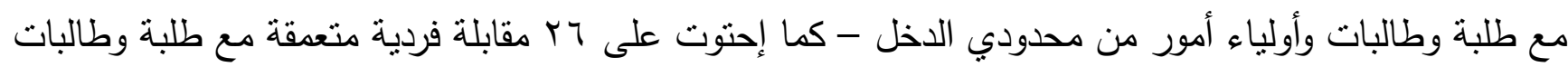
يحصل حوالى نصفهم على دعم مالى من الجامعة أو من جهات أخرى.

وقد أوضحت نتائج الدراسة أن التكاليف الفعلية (مثال الكتب الدراسية والدروس الخصوصية والأدوات والمستلزمات

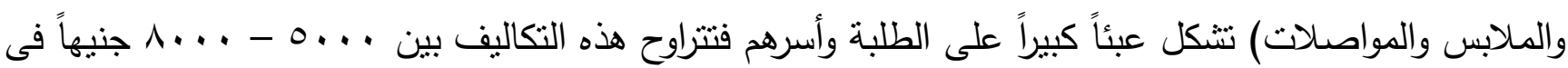
العام الدراسى الواحد حسب نوع الكلية ومحل سكن الطالب كما أن أسر الطالبات أحيانا ما يتحملون تكلفة أعلى ولى واهلى

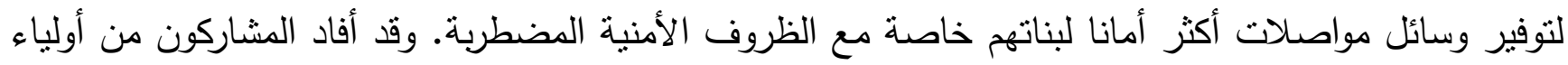
الأمور أنه بالرغم من ظروفهم الاقتصادية الصعبة إلا أنهم يحرصون على تعليم ابنائهم وبناتهم ويتبعون

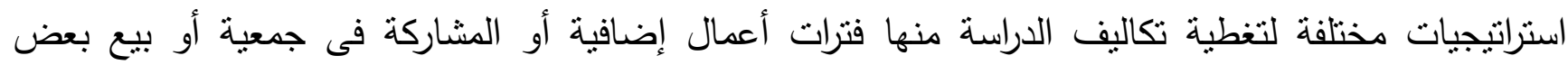

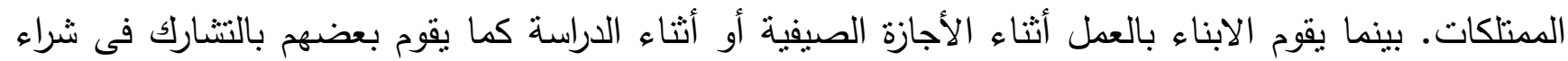
الكتب أو الدذكرات الدراسية.

وعن الدعم الذى تقدمه الجامعة للطلاب محدودى الدخل إتضح أنه لا يوجد لدى الطلبة والطالبات دراية كافية عن

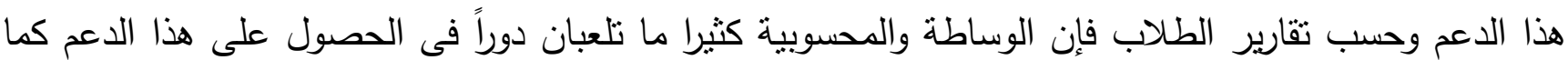
أن اجراءات التقدم للحصول على الدعم طويلة ومعقدة مما يجعل الكثير من الطلاب يحجمون عن التقام للحصول عليه.

وتتير نتائج هذه الدراسة إلى ضرورة تضافر الجهود بين الجهات الحكومية والأهلية والقطاع الخاص من أجل خفض تلك النفقات الفعلية والتظلب عليها حتى لا تحول دون تكافؤ الفرص بين الطلاب من الثرائح الاجتماعية المختلفة وتحقيق الحرالك الاجتماعي المنشود. 
تنتير نتائج مسح النشئ والثباب 9 9 . ب إلى انخفاض معدلات الالتحاق بالتعليم الجامعى بين الطبقات الأكثر فقراً

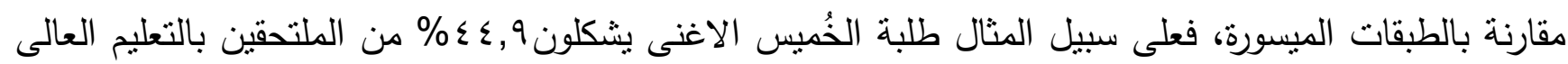

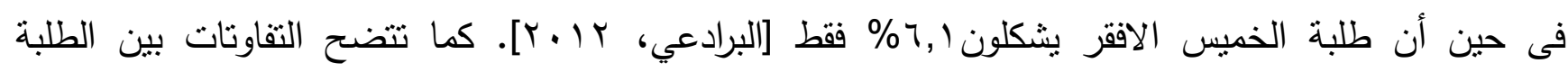

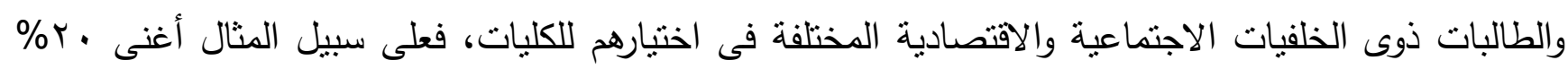

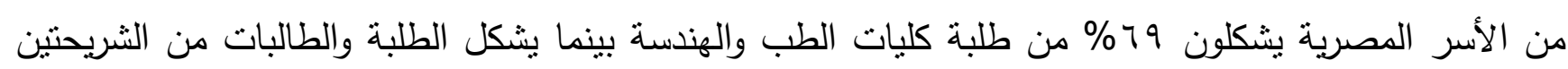

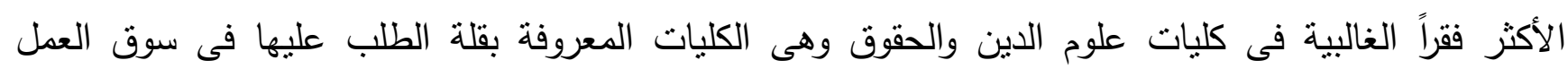

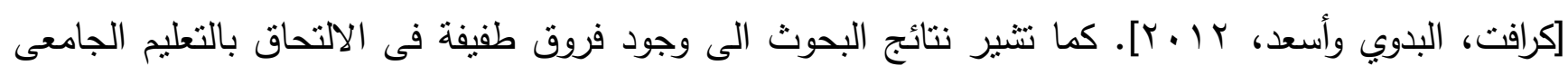
حسب النوع الاجتماعى ولكن تتضح هذه الفروق فى ريف الوجه القبلى حيث تمثل الإناث الملتحقات بالتعليم

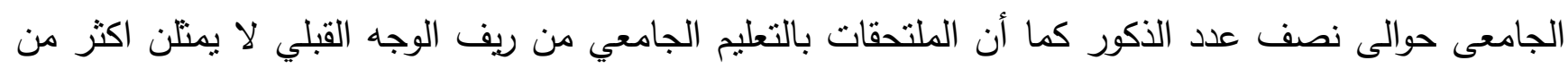
. 1 ا من مجموع الفتيات فى السن الجامعى.

وتثير النتائج السابقة بعض التساؤلات حول الأسباب التى تجعل الأسر محدودة الدخل تحجم عن إرسال أبنائها

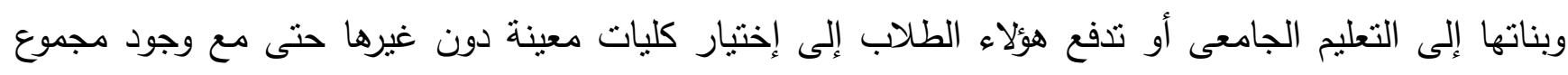

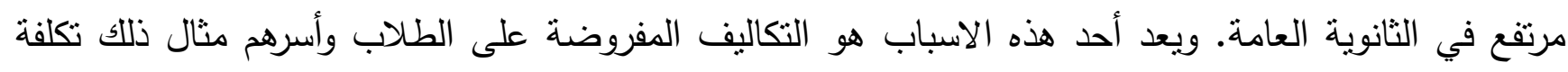

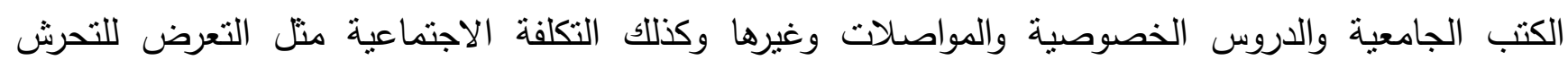
الجنسى أو انخفاض فرص الزواج للفتيات أو تكلفة الفرصة البديلة مثال فرص العمل الضائعة نتيجة للالتحاق ولاق بالجامعة.

لذا فقد تم إجراء هذه الدراسة الإستكثافية بغرض التعرف على رؤى الطلاب وأولياء الأمور حول تكاليف (بما فى التى

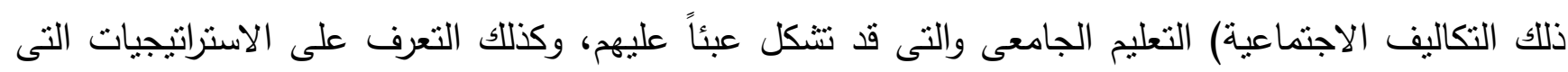

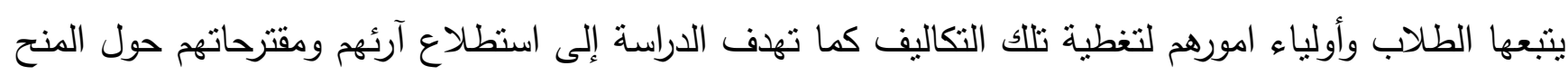

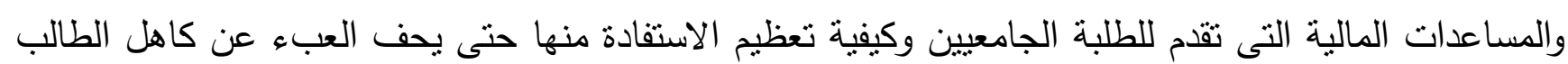
وأسرته وتتحقق العدالة وتكافؤ الفرص فى ظل سياسة الدولة التى تكفل التعليم المجانى للجميع. 


\section{منهجية الارلسة}

اتبعت الدراسة المنهج الكيفى حيث تم إجراء r I مجموعة نقاش بؤرية مع طلبة وطلبات وأولياء أمور بمحافظتي سوهاج والإسكندرية وكذللك بr مقابلة فردية متعمقة مع طلبة وطالبات من كليات عملية ونظرية بنفس المحافظتني.

\section{مجموعات النقاش البؤرية}

تم اجراء 1 مجموعات نقاش بؤرية مع طلبة وطالبات من كليات عملية ونظرية ' بواقع ع مجموعات فى كل محافظة (مجموعتين للذكور ومجموعتين للإناث) وقد بلغ اجمالى عدد المشاركين سا طالبا وطالبة تراوحت اعمارهم ما بين 9 ا-بr عاما. وقد روعى فى إختيار عينة الطلاب أن يكون الطالب أو الطالبة قد إجتاز السنة الأولى بحيث يكون لايهم حصيلة من المعلومات والخبرات المتعلقة بتكلفة التعليم. وقد روعي في اختيار عينة الطلبه والطالبات أن يكونوا من طلبة الجامعات الحكومية وأن ينتموا لأسر محدودة الدخل وأن يكون بعضهم ممن يسكنون بالمناطق الريفية.

كما تم إجراء ء مجموعات نقاش بؤرية مع اباء وامهات من محدودى الدخل ممن لديهم ابناء أو بنات يدرسون بالجامعة (بواقع r مجموعة نقاش بؤرية بكل محافظة) وبلغ عدد المشاركين سب ابا واما. وتنوعت وظائف الاباء فى العينة ما بين سائق - موظف - فنى - عامل - صاحب ورشة - مزارع. أما بالنسبة لعينة الأمهات فكانت الغالبية العظمى منهن ربات بيوت، بينما قلة منهن يعملن موظفات فى وظائف إدارية.

\section{المقابلاث القردية المتعمقة}

تكونت عينة المقابلات الفردية المتعمقة من جr طالباً وطالبة من كليات نظرية وعملية ممن ينتمون لأسر محدودة الدخل (Y ا فى سوهاج و ا أفى الاسكندرية) وكان من بين هؤلاء الطلبة اثثين من المكفوفين وقد أفاد 10 من الطلاب المشاركين بحصولهم على دعم مالى سواء من الجامعة أو الجمعيات الأهلية. 
فيما يلى عرض لنتائج مجموعات النقاش البؤرية وكذلك المقابلات الفردية المتعدقة وفقاً لنوع التكلفة والاستراتيجيات المتبعة للتغلب على هذه التكاليف:

\section{النقفقات الرسمبة وغير الرسمبة}

\section{اللرسوم الدراسبية}

لم يكن هناك فرق في الرسوم الدراسية بين الطلبة والطالبات سواء فى سوهاج أو الاسكندرية وكذللك فى الكليات العملية أوالنظرية، كما أنها تعد أقل التكاليف التى يتحملها الطلبة وأسرهم. وبظهر الاختلاف فقط فى أن المبالغ التى يدفعها الطلبة المنتسبون أعلى مما يدفعه الطلبة المنتظمون، هذا بالنسبة للكليات النظرية، وكذلك الرسوم الدراسية لكلية الفنون الجميلة تعد أعلى من باقى الكليات.

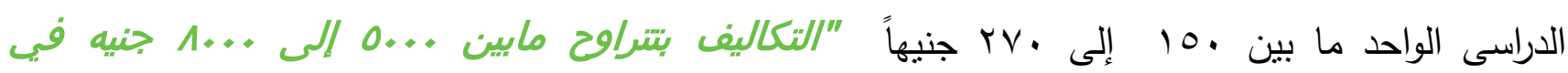

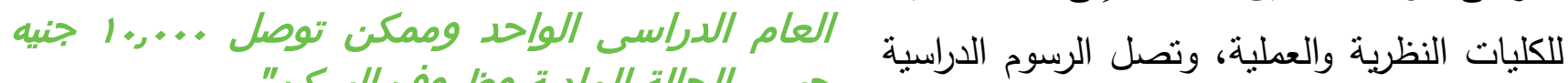

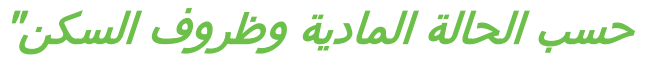
للطلبة المنتسبين مابين 0.

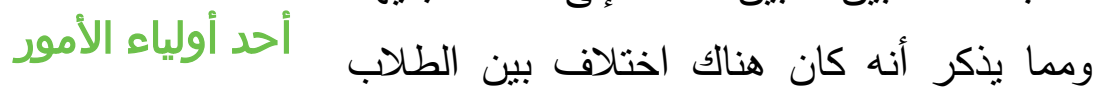
وأولياء الأمور فى تحديد المصروفات، حيث أن ان هن بعض أولياء الأمور ذكروا التكلفة الكلية للفصل الدراسى من مصروفات دراسية وكتب ومواصلات وملابس دون تحديد قيمة الرسوم منفصلة، وهذا منطقى لأنهم يتذكرون ما يتحملونه من تكلفة إجمالية للتعليم.

وذكر طلبة وطالبات كلية العلوم أنهم يتحملون تكاليف أكثر من غيرهم لأن كليتهم تطبق نظام الساعات المعتمدة، ويتكلف تسجيل المادة الواحدة فى الفصل الدراسى الصيفى مبلغ . . اجنيه كرسوم وكانت فى السابق .0 جنيهاً ويتم حاليا مناقتة زيادة هذا المبلغ إلى •0 اجنيه. وفى حالة تعديل أو استبدال مادة من المواد يتم دفع مبلغ جنيهات عن المادة أما فى حالة الحذف فيتم دفع مبلغ .0 جنيه.

وأجمع أفراد العينة من الطلبة والطالبات فى سوهاج والإسكندربة أنهم يعانون عند دفع هذه الرسوم من الإجراءات المعقدة، ويطلقون عليها " سوم الكارنبية" أى الرسوم التى يحصلون بموجبها على "البطاقة الجامعية". فهم يدفعون 
مبلغاً تحت بند الرسوم فى مكان مخصص ثم يقومون بدفع مبالغ أخرى صغيرة ما بين ـ ال - .0 جنيهاً تختلف

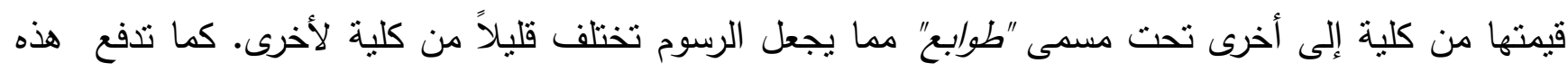

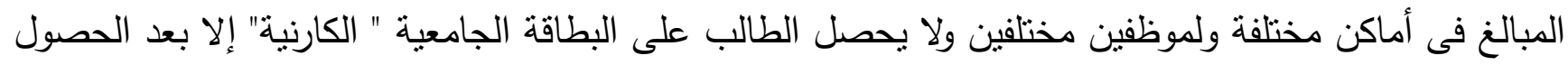

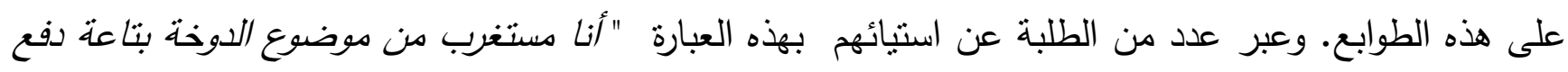
الطوابع. ليه ماتدفش الرسوم كلها مع بعض في فلى مكان واحد". وقد اقترح معظم الطلبة والطالبات فى سوهاج

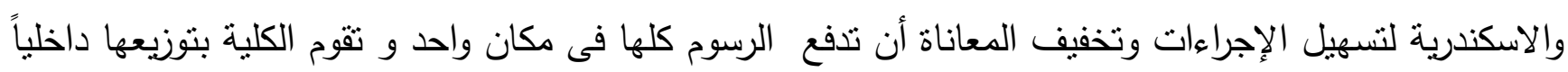
بمعرفتها لأن هذا إجراء داخلى لاعلاقة للطلاب به.

ومن ناحية أخرى أكدت الغالبية العظمى التي خضعت للمقابلات المتعقة أن التكاليف التى تدفع للتعليم الجامعى

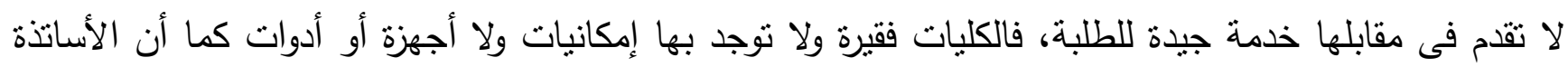

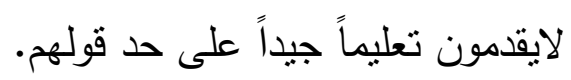

"احنا ساعات كتير ينروح الكلية وتتكلف مواصلات ونتنظر الدكتور

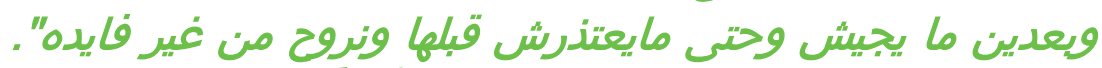

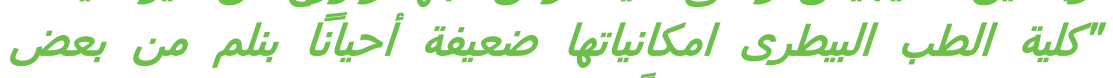

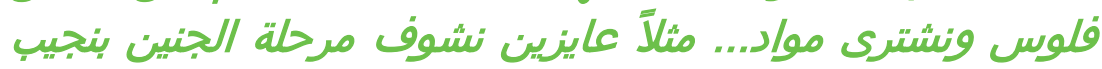
بيض سمان على حساينا"

\section{طالبة بكلية طب بيطرى}

كما تبين أن هناك عدم ثقة من قبل الطلاب وأولياء الأمور تجاه الجامعة فهم يعتقدون أنها تريد الحصول على الحى

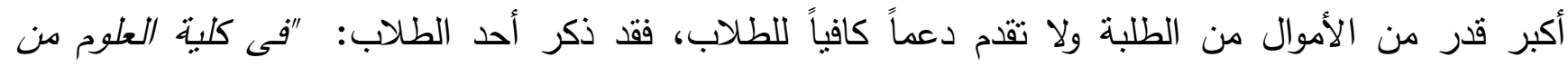
الكفترض أن الفصل الدراسى الصنيفى يوفر للطالب نفقات ووقت ولكن مصاريف الساعة الواحلة . . ( جنية" بينما

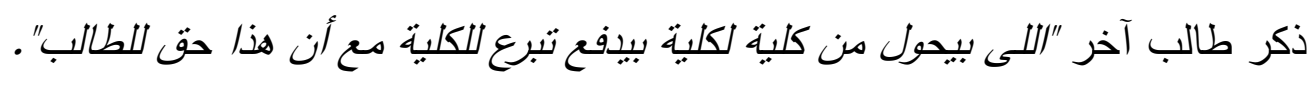

الكتب الجامعية والمذكرات

تشكل تكاليف الكتب الجامعية إحدى العقبات المادية بالنسبة للطلبة والطالبات لأنها تزيد من تكاليف التعليم، فقد

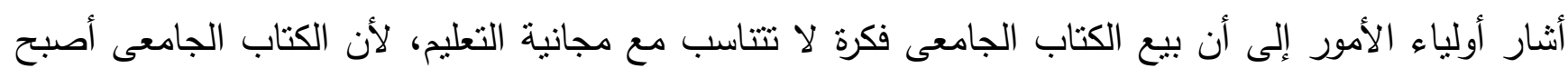

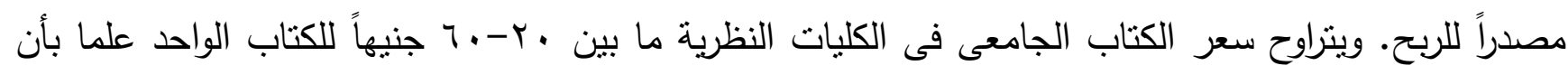

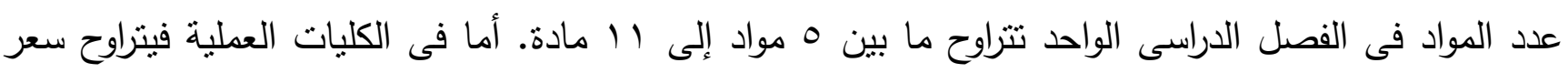

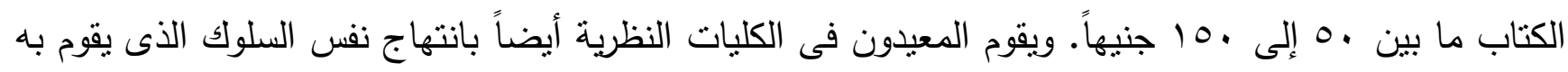


أساتنتهم فيعيدون تلخيص الكتب وتبسيطها وبيعها للطلبة فى صورة مذكرات (ملازم) ويتراوح سعر هذه الملازم ما

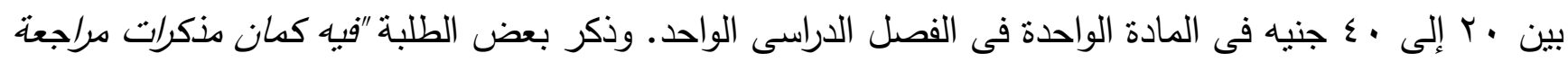

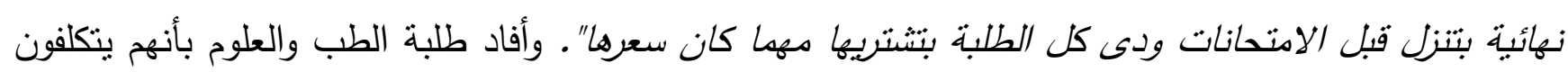

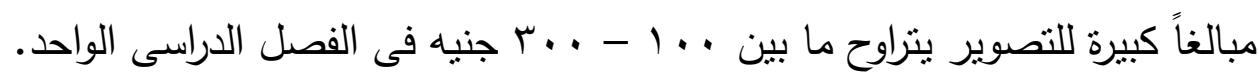

وقد أجمعت عينة البحث من طلاب وأولياء أمور فى سوهاج والاسكندرية على أن الأساتذة يلجأون إلى عدة أساليب

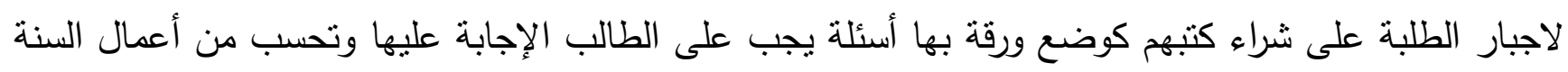

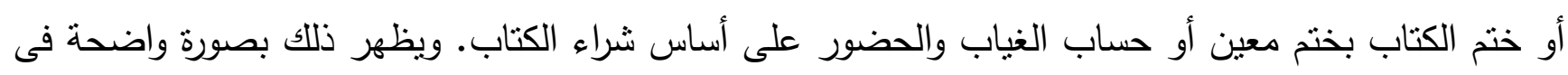
الكليات النظرية.

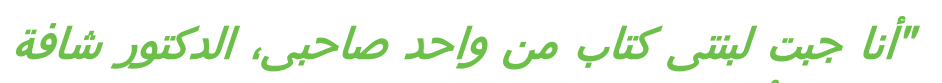

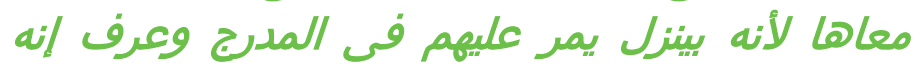

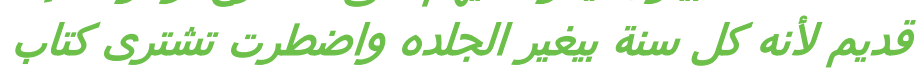

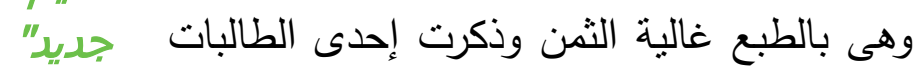

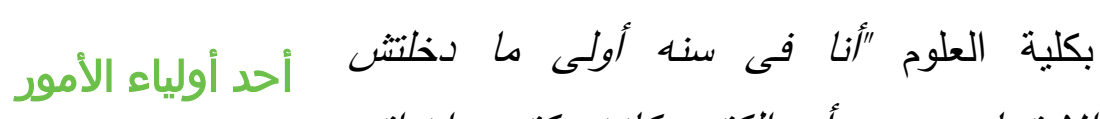

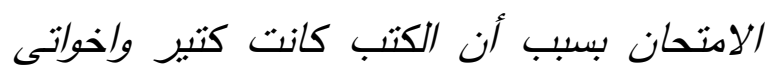

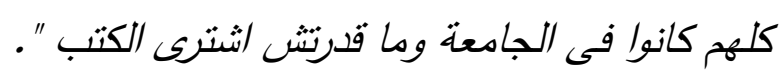

وذكر الطالبين المكفوفين بالعينه أنهم يتكلفون أكثر من غيرهم بالنسبة للكتب وأن الأساتذة لا يراعون ظروف ذوى

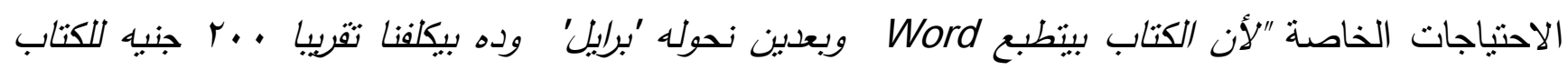

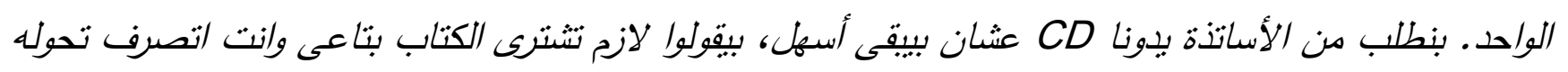
كمبيوتر أو صوتى مالبش دعوه ".

\section{الدروس الخصوصية}

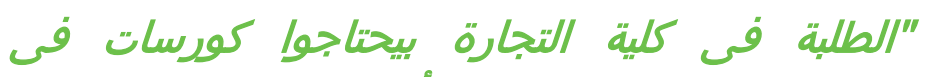

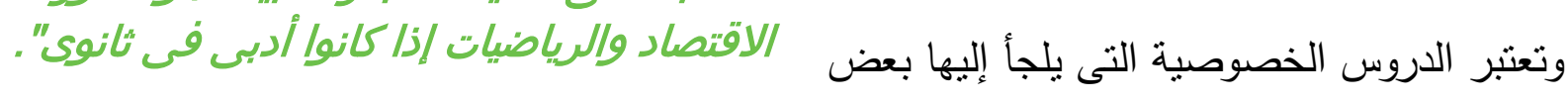

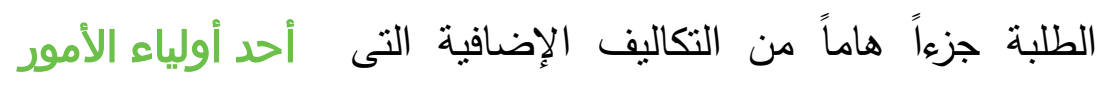

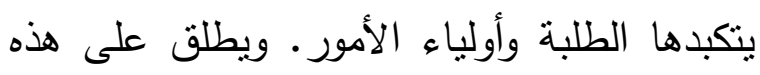

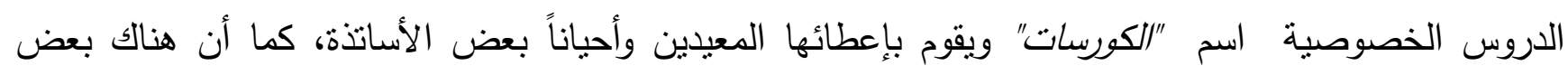

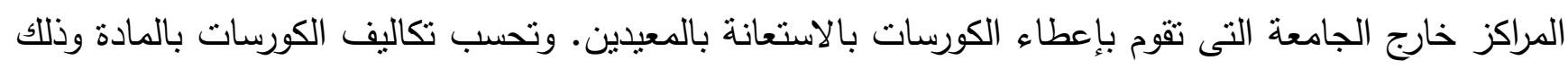

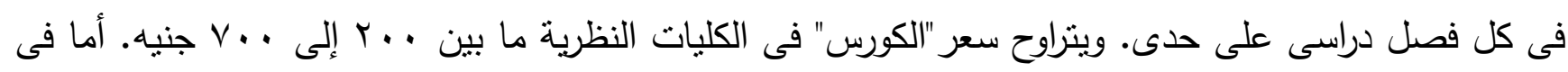


الكليات العملية فيصل سعر المادة من ... .1 إلى . .10 جنيه، وذكر أحد الطلبة فى كلية الهندسة "أنا كنت

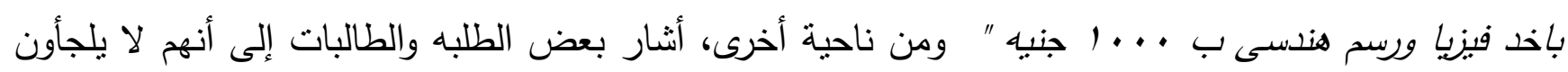
إلى الدروس الخصوصية لارتفاع أسعارها وعدم قدرتهم المالية.

\section{الأدوات والأجهزة}

يحتاج الطلبة والطالبات فى الكليات العملية إلى بعض التكاليف لشراء أدوات وأجهزة ترتبط ارتباطاً وثيقاً بتخصصاتهم، فطلبة كلية الطب يحتاجون إلى شراء سماعة وجهاز ضغط والبالطو بحوالي . .. جنيه وتظل هذه

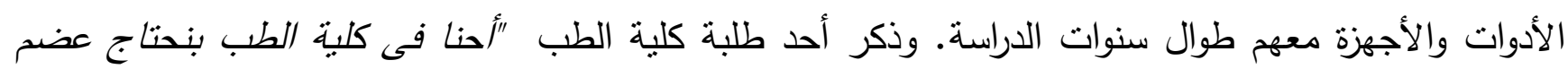
القطعة من r إلى ع جنبه والهيكل الكامل بـ . . . 1 جنيه".

أما باقى الكليات فتحسب تكاليف هذه الأدوات بالفصل الدراسى، فمثلاً يحتاج طلبة الهندسة إلى شراء مسطرة حرف .

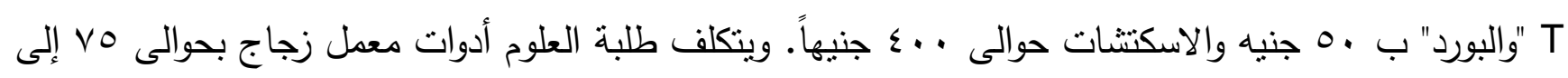

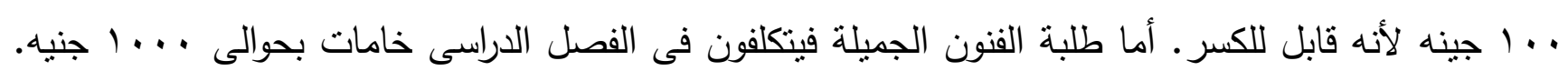

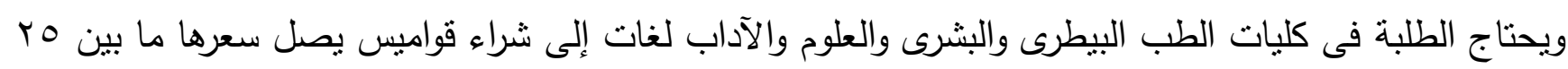
إلى .10 جينه ولكنها تظل معهم طوال سنوات الدراسة.

المواصلات

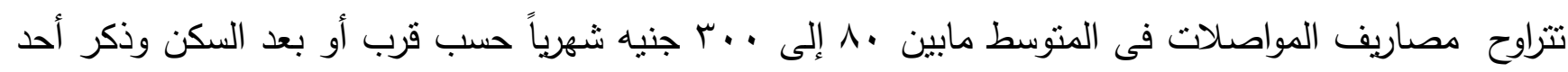

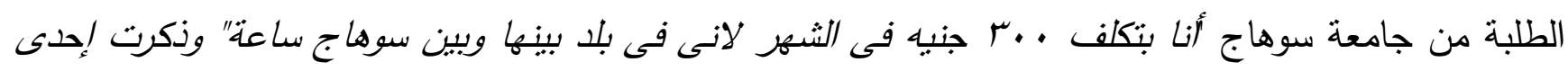

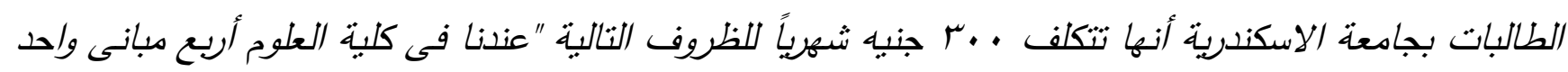

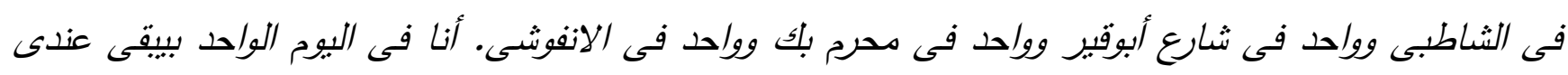

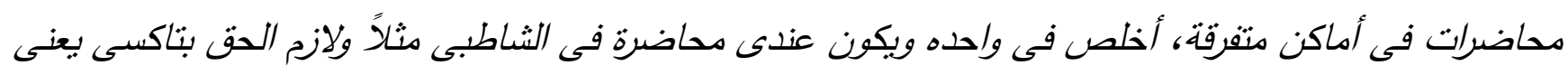

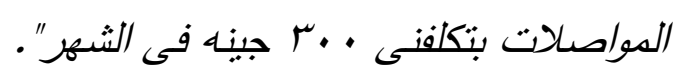

ومما يذكر أن تكلفة المواصلات ترتفع للطالبات عن الذكور، فقد ذكرت بعض الطالبات أنه فى فنرة المشاكل

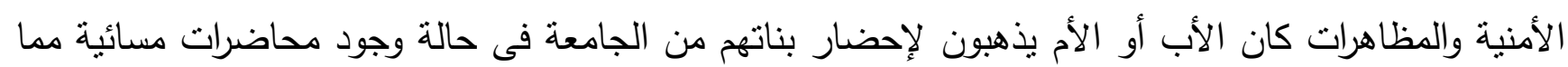

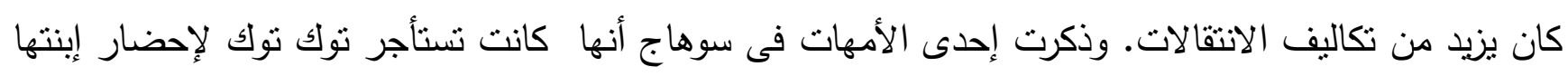

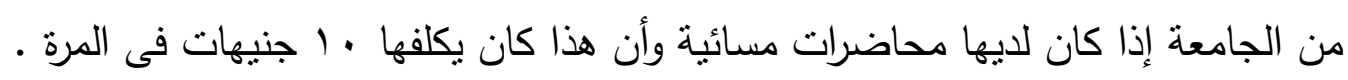


التخفيضات أو قبل الأعياد، أو الثراء بالتقسيط لتقليل المصاريف وتتكلف بعض الطالبات مبلغاً إضافياً لأدوات

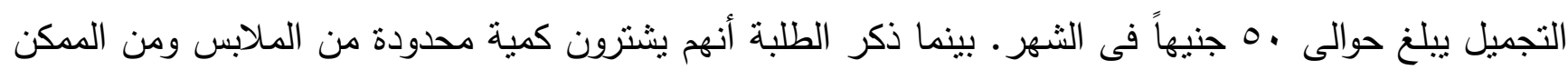

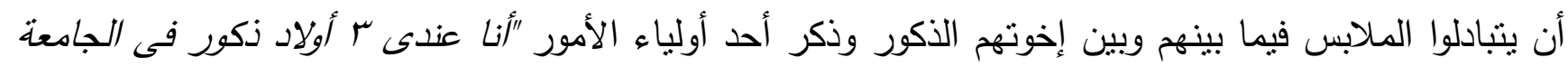
بيبذلوا اللبس مع بعض".

\section{المحمول والانترنت}

ذكرت نسبة كبيرة من العينة أن لايهم تكاليف شهرية خاصة بالتليفون المحمول والانترنت والتى قد تصل إلى ..1

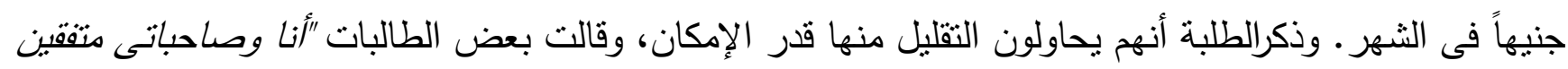

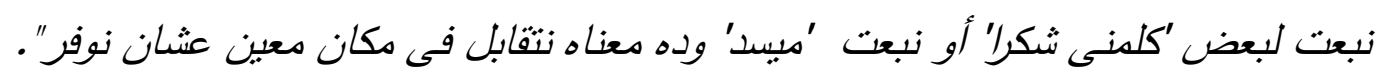

\section{قصة كثاح (رقم ا )}

سـارة طالبـة بالصـف الثالـث بكليـة صـيلئة

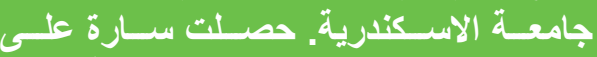

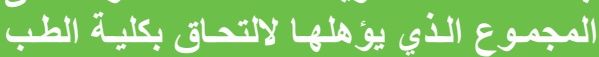

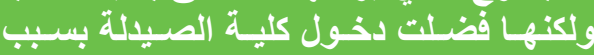

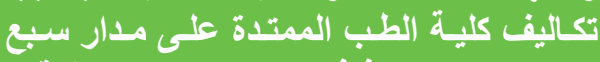

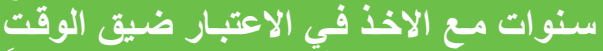

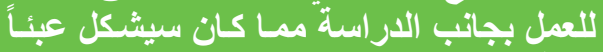

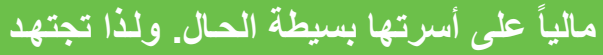

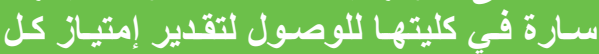

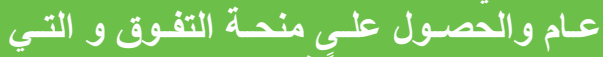

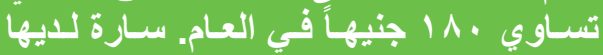

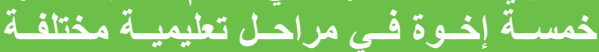

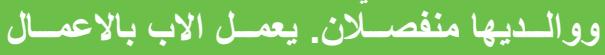

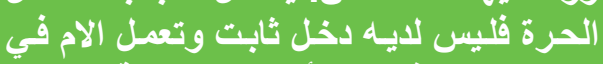

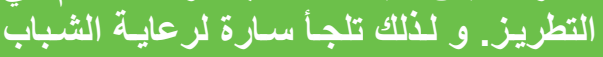

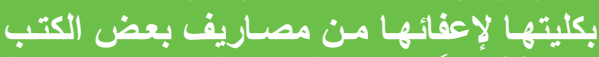

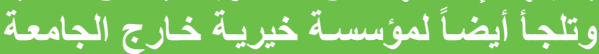

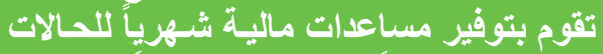

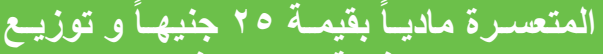

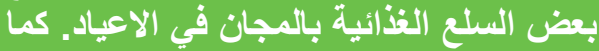

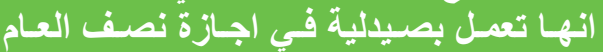

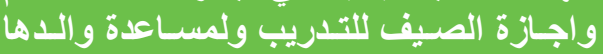

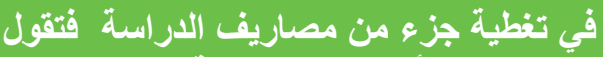

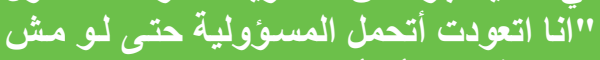

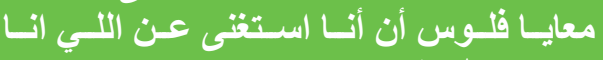

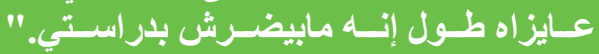

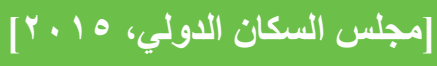

مواجهة تكاليف التعليم الجامعى

إستراتيجيات الطلاب وأولياء الأمور للتظلب على التكاليف

تبين من المناقثنات مع الطلبة والطالبات وأولياء الأمور أن هناك

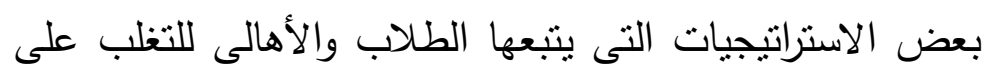

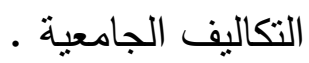

ويعمل الغالبية العظمى من الطلبة والطالبات فى الأجازة الصيفية

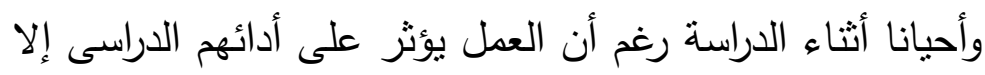

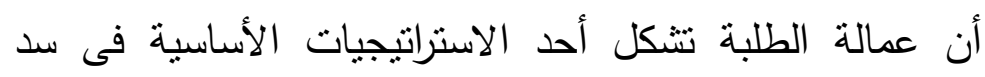
النفقات. وتزيد عمالة الطالبات فى الاسكندرية عنها فى سوهاج

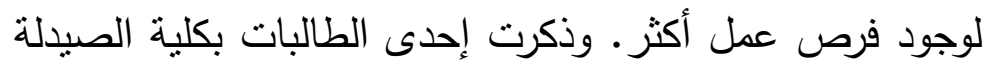

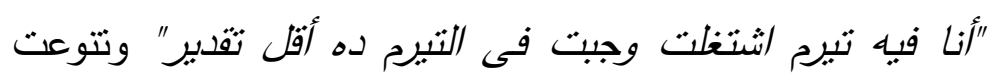

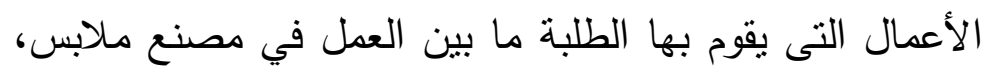

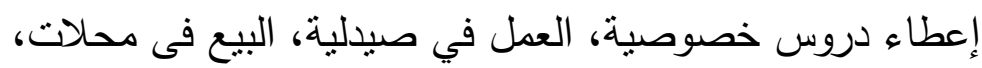

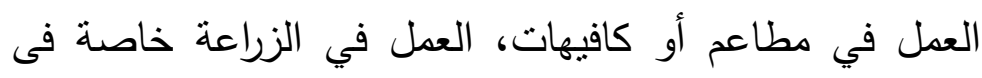

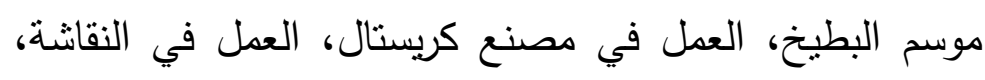

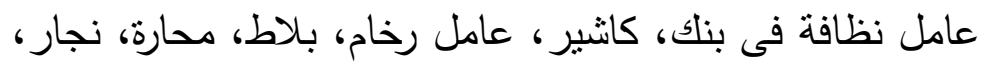
دليفرى، العمل فى حضانة (أنظر قصص الكفاح رقم ( ). 
أما بالنسبة لمصاريف الكتب والمذكرات في الكليات النظرية فيقوم البعض بتصويرها من زملائهم أو ينتاركون فى شراء مذكرة ويصورونها بعددهم، وفى الكليات العملية يقوم البعض بتصوير الكتب من بعض الزملاء ولكنهم

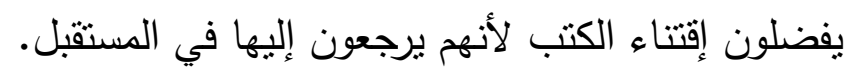

وبالنسبة لتكاليف المواصلات، يقلل البعض وخاصة طلبة الكليات النظرية من عدد مرات الذهاب للكلية لتوفير مصاريف المواصلات أو الاقتصاد فى مصاريف الأكل خاصة بين الطلبة والطالبات المقيمين فى المدن الجامعية.

أما بالنسبة لأولياء الأمور، فتلخصت الاستراتيجيات فى عمل الآباء عملاً إضافياً كأن يكون موظفاً فى الصباح

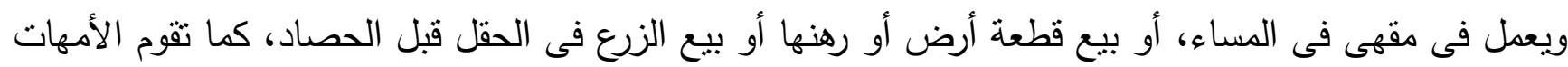

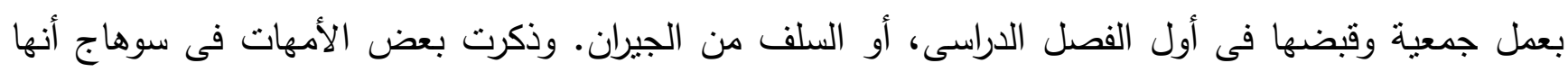
تقوم بتربية بعض الطيور أو الحيوانات وبيعها والصرف منها على نفي نفات تعليم ابنائهن.

وذكر بعض أولياء الأمور أن هناك من بزوجون بناتهم حتى يقللوا من عبء المصاريف إلا أن الزواج يؤدي في

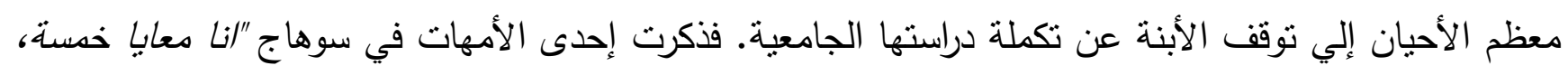

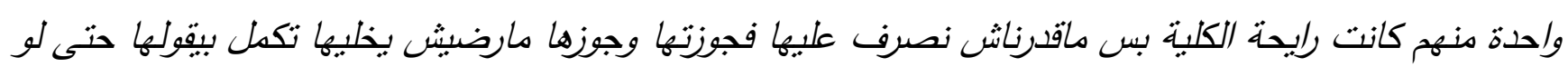

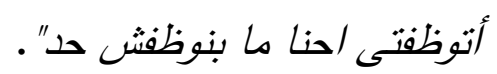

الدعم الجامعى

تبين من مجموعات النقاش والمقابلات المتعقة أنه لايوجد لدى الطلاب معلومات كافية وواضحة عن الدعم الذى الذى

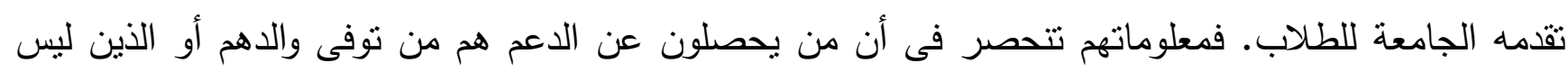

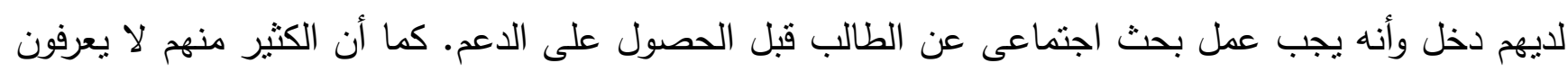

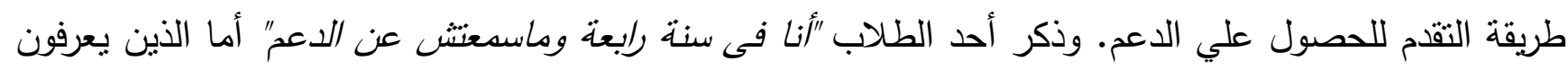

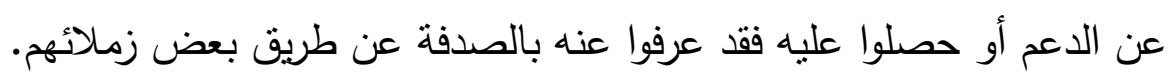

وأجمع الطلبة والطالبات أن الاجراءات الخاصة بالحصول على الدعم معقدة وطويلة، وذكرت إحدى الطالبات

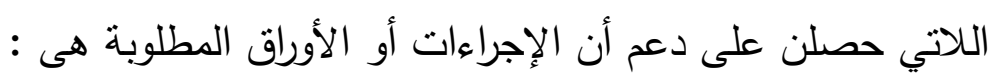

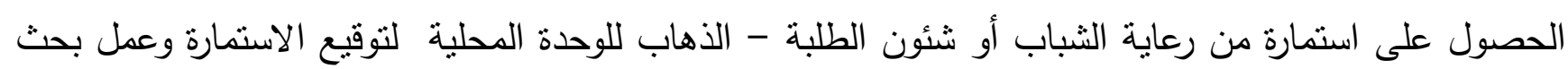
حالة - إحضار بيان من الإدارة الزراعية بعدم وجود حيازة زراعية - صورة بيان بالمعاش من التأمينات - شهادة

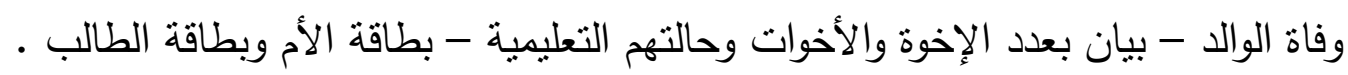




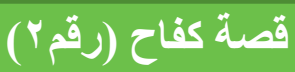

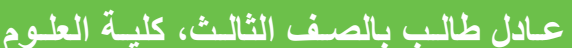

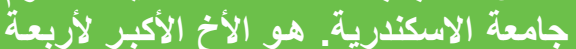

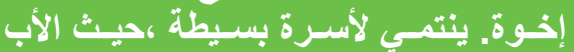

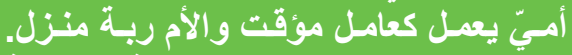

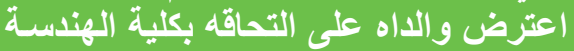

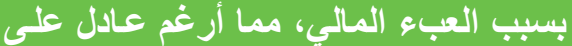

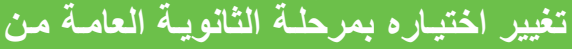

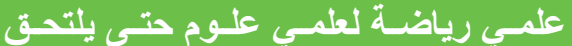

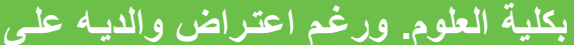

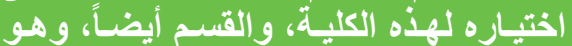

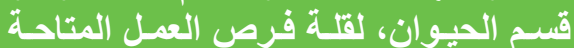

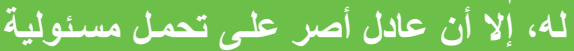

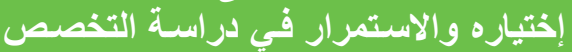

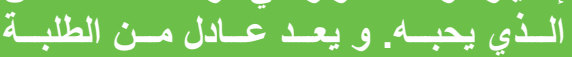

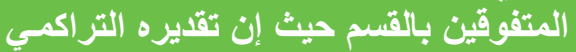

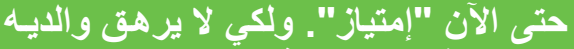

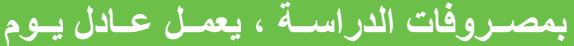

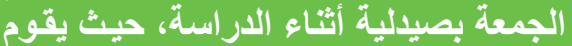

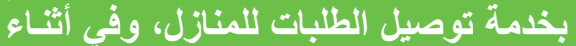

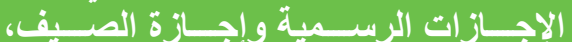

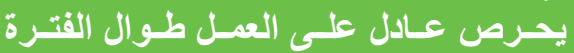

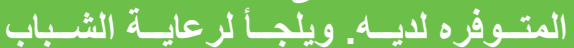

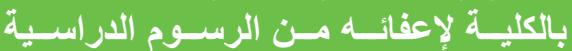

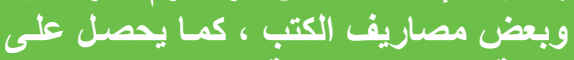

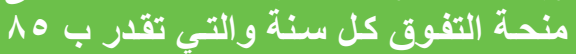

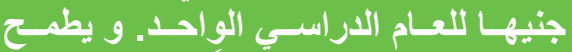

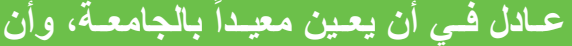

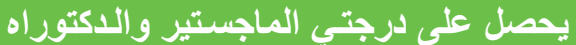

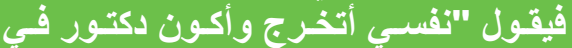

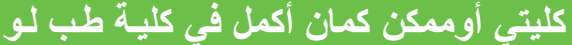

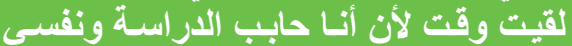

وتبين أيضاً أن نوع الدعم الذى يقدم قد يكون فى صورة

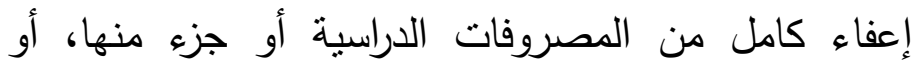
الحصول على كتاب واحد مجاناً (أنظر قضية الكفاح رقم r) (برى الطلبة والطالبات أن هذا الدعم هزيل ولا يستحق العناء. فذكر أحد أولياء الأمور "الإعفاء من الكارنية مش الهاع معضلة، المشكلة فى باقى المصاريف زى الكتب والتصوير التهري

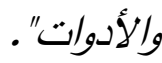

ويعتقد الكثير من الطلبة والطالبات فى سوهاج والاسكندية

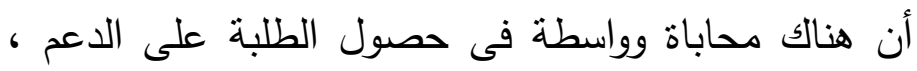

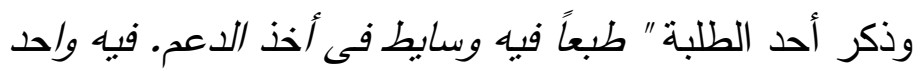
صاحبى خالته هى اللى ماسكة الموضوع ده عندنا فى الكلية بياخد دعم من غير مايجيب كل الأوراق دى. مابييفعش

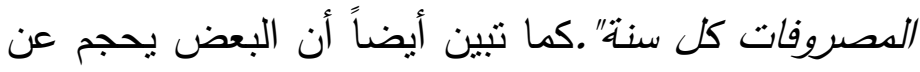

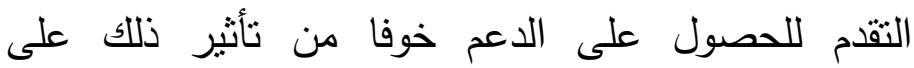

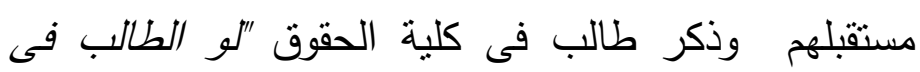

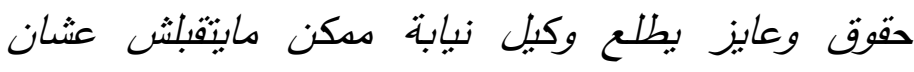
حيتحط فى الدلف بتاعه إنه واخد دعم من الجامعة أى أنه

من عائلة ققبية".

وذكرت الغالبية العظمى من الطلبة والطالبات أنهم يترددون فى التقدم للحصول على الدعم للمعاملة السيئة التى يعاملهم

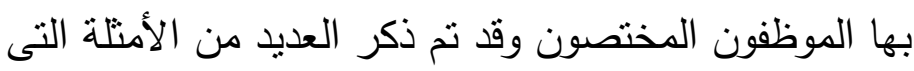

وذكرت إحدى الطالبات وهى الثانية على الدفعة "أنا اتعرضت لموقف صعب مع إحدى الموظفات، أنا رحت عملت

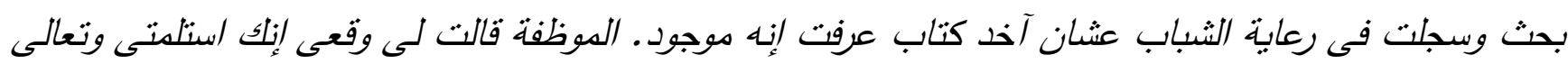
خديه الأسبوع الجاى ورحت فى الميعاد قالت لى إنت أختنيه وحصل حوار مش كويس معناه إنى حرامية".

وأفاد بعض أفراد العينة بأنهم يحصلون على ما يسمى بمكافأة تفوق والتي قد تتراوح ما بين .1 إلى .10 جنيهاً

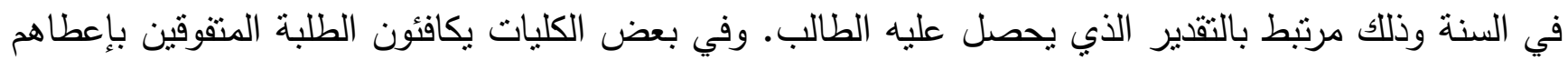


هدايا قيمة مثل "التابلت". وبمناقثة نظام منحة التقوق وافق أفراد العينة على فكرة مكافأة المتفوقين ولكنهم طالبوا

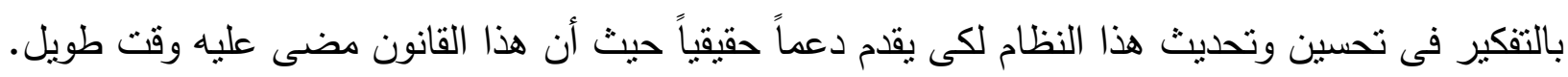

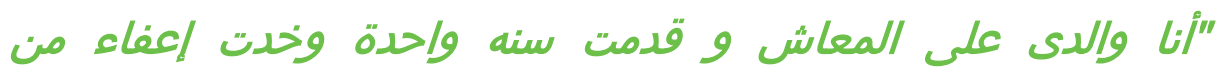

المصاريف، حسيت من المعاملة وطريقة كلام المام الموظفة بالإهانة كإنى

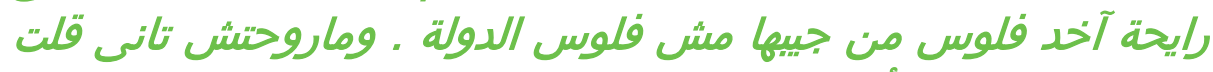

ماما تسنلف لى ولا أحس في الإهانة ".

إحدى الطالبات

وتم سؤال أفراد العينة حول مدى موافقتهم على تقديم الجامعة قروض للطلاب ترد بعد تخرجهم ، ولكن هذه الفكرة

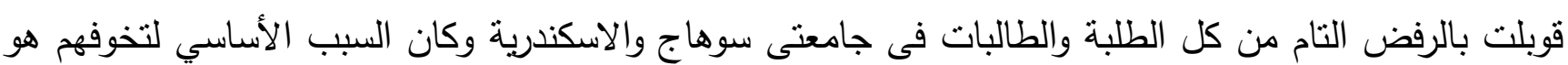

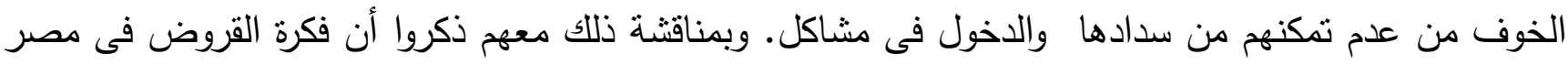

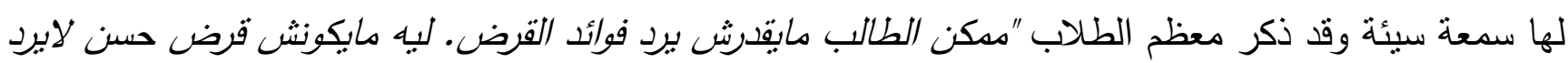
،ؤ أن برتبط بتقليم خدمة أو عمل كمحو أمية عدد من الناس".

الاعم الخارجي

أما عن المصادر الخارجية لتقديم الدعم للطلاب فكان هناك شبه إجماع على أن الجمعيات الأهلية ليس لها دور

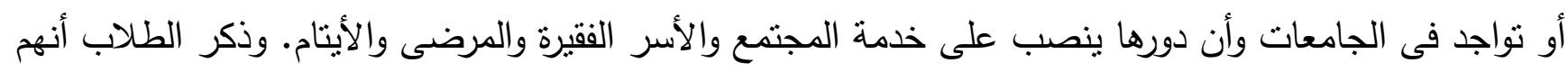

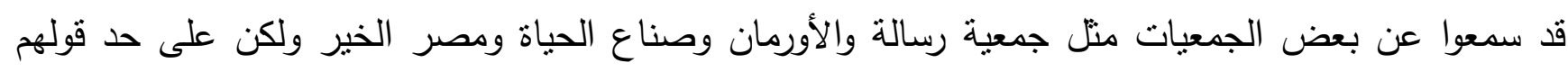

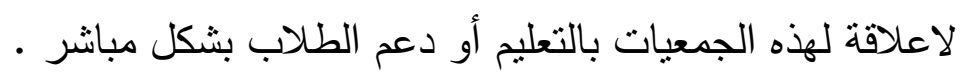

ومع ذلك فقد تبين من المقابلات الفردية المتعمقة أن نسبة كبيرة من الطلبة فى العينة من جامعة الاسكندرية يحصلون على دعم من الجامعة، وفى نفس الوقت قامت رعاية الثباب بتحويلهم إلى إحدى الجمعيات المهتمه فئه

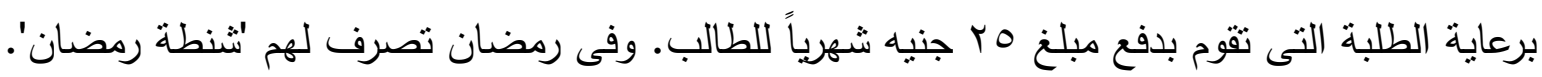

وذكر بعض الطلبة والطالبات أنه توجد بعض المساجد التى تدفع مبالغ مالية بسيطة شهرياً بشرط تقيم ما يثبت وضع الطالب الدراسى وأنه ناجح. ويوجد أيضاً بعض الجمعيات توفر ملابس للطلبة بالمجان أو بأسعار رمزية على حسب حالة الطالب الاجتماعية والاقتصادية. 


\section{الخلاصة والتوصيات}

الخلاصة

وعلي الرغم مما حققته سياسة مجانية التعليم الجامعي من نجاح في النصف الأخير من القرن الماضي من تحقيق

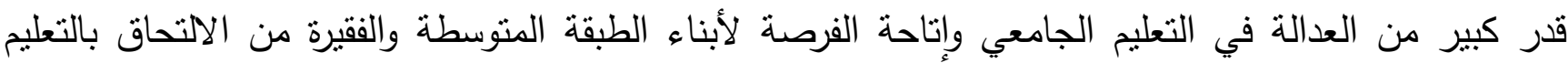

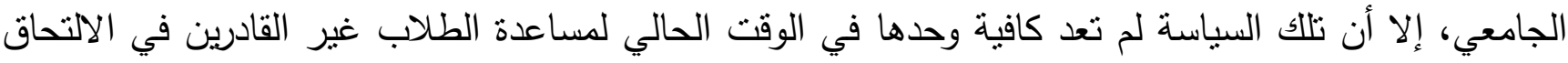

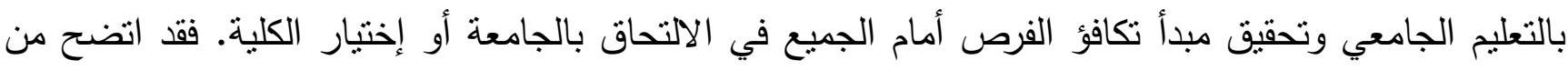
خلال هذه الدراسة الاستكثافية ارتفاع تكلفة التعليم التي يتحملها الطالب، كما إتضح وجود تفاوت كبير في تلكك

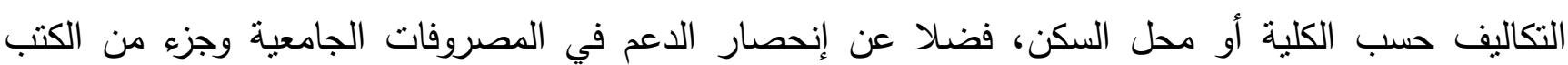

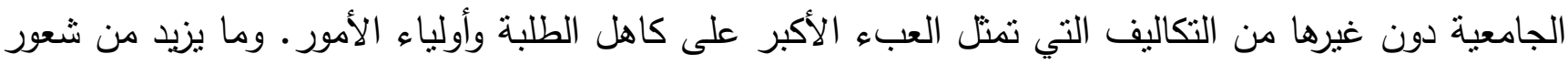
الطلبة وأولياء الامور بعبء تلاك التكاليف هو عدم علمهم بما تتحملة الدولة من تكلفة لتطبيق سياسة مجانية التعليم

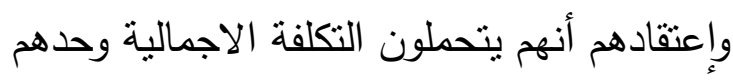

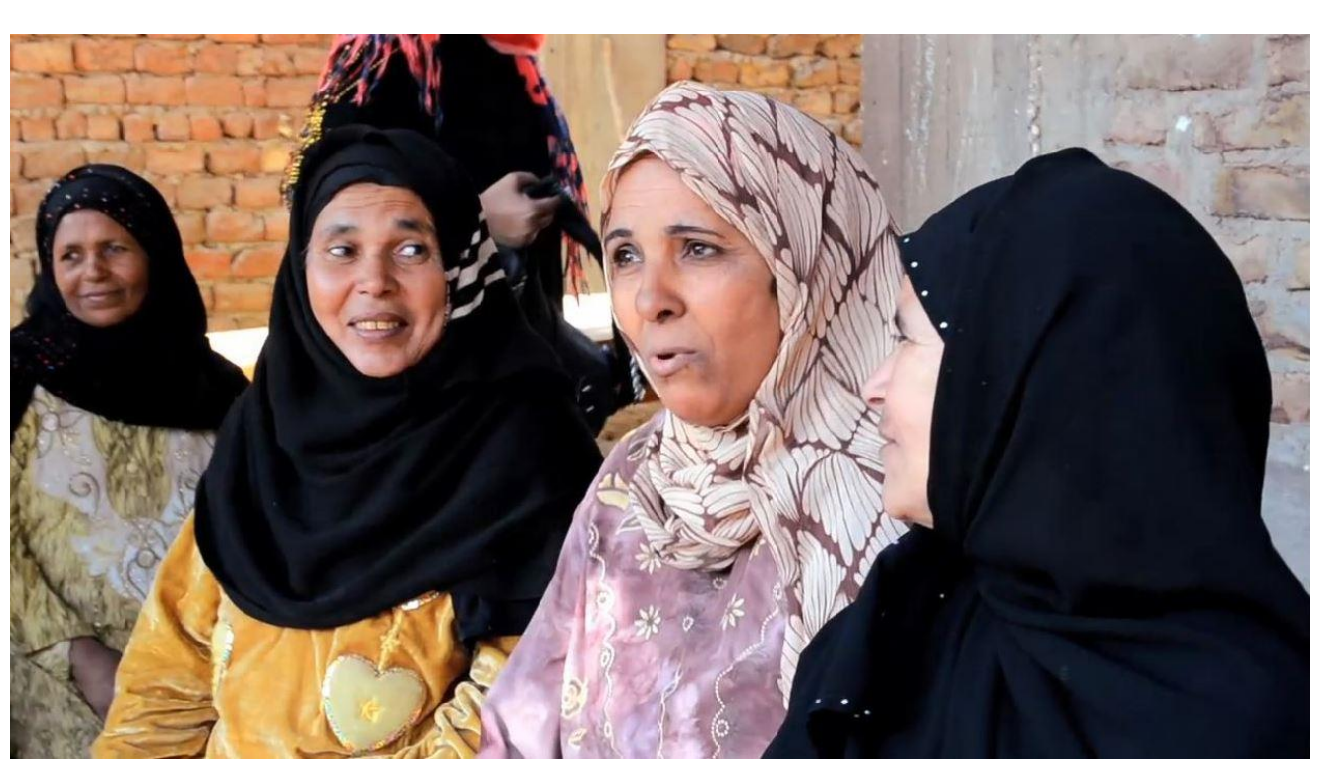

ونتير هذه النتائج إلى أهمبـة تضـافر الجهـود بين الهيئات الحكوميـة وغيــــــر الحكوميــــــة

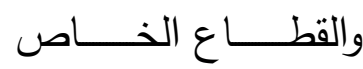
والإعــلام مــن أجـلـ خفض هـذه التكـاليف ومســـــاعدة الطــــلاب وأوليـاء الأمــور علـى

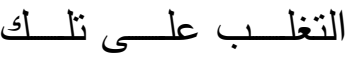
النفقات بما يحقق تكافؤ الفرص في الالتحاق بالتعليم الجامعي وإجتيازه بنجاح ومن ثم تحقيق الحراك الإجتماعي المنشود. وفيمـا يلي مجموعـة من المقترحات والتوصيات التي طرحها بعض الطـلاب وأولياء الأمور من خـلال الدراسـة وكذلك نخبة من الخبراء والمتخصصين الذين شـاركوا في عدد من الحلقات النقاشية التي عقدها مجلس السكان الدولي في هذا الثأن. 
التوسع في نطاق الدعم ليشمل كافة الدصروفات التي يتحملها الطالب مع تشجيع الطلبة القادين ورجال الاعمال على المساهمة في صندوق دعم الطلبة لزيادة موارده وبالتالي قدرته على تقديم دعم افضل لُصل للطلاب غير القادرين. الإعلان عن الدعم المتاح وإجراءته بصورة واضحة للطلبة وتعديل الاجراءات الحالية المطلوبة للحصول

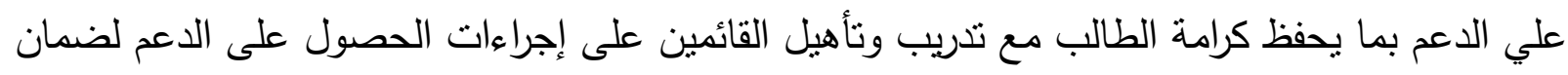

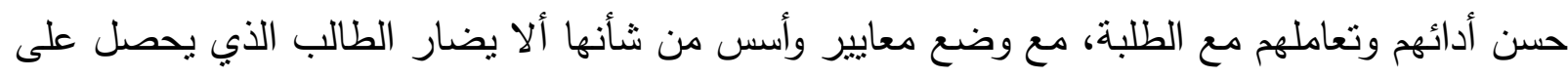
دعم في المستقبل مثل القبول في الخارجية أو النيابة العامة.

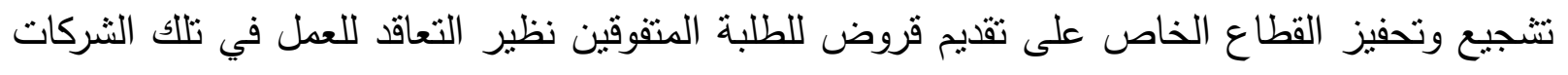

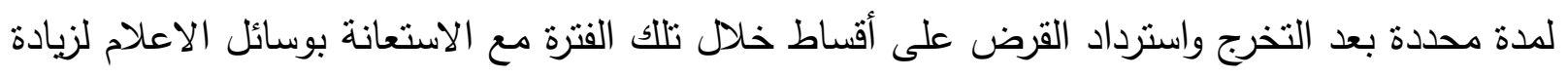
تقبل المجتمع لفكرة حصول الطلبة غير القادرين على قروض دراسية لمواجهة تكاليف التعليم.

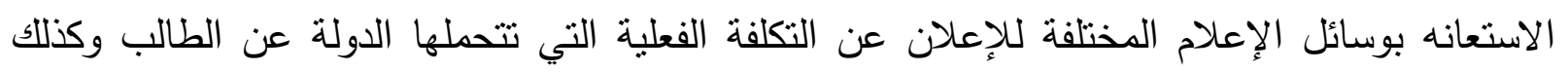

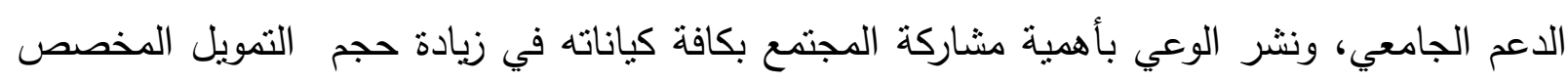
لاعم الطلاب. وضع نظام يسمح للجامعة بقبول الوقف الخيري وادارته ليخصص عائده إلي دعم الطلاب غير القادرين.

\section{المساهدة في خفض تكلقة الكتب والمستلزمات اللارسية}

اتاحة الكتاب الجامعي عبر موقع الاككتروني أو تحميله على قرص ممغنط أو توفيره بمكتبات الجامعة

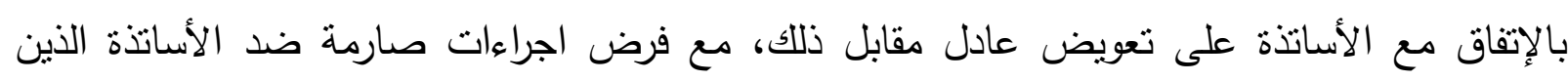
يفرضون شراء الكتاب على الطلبة.

توفير وسائل انتقال آمنة وبأجر رمزي من وإلي الجامعة خاصة للطالبات، وذلك من خلال الجامعة مبانشرة

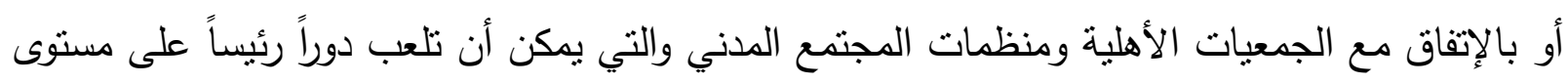
القرى والمناطق الريفية في توفير وسائل إنتقال آمنة للطلاب. 
• التعاقد مع جهات لتوريد الأدوات والمستلزمات التي يحتاجها الطلاب لضمان توفيرها بأفضل الأسعار،

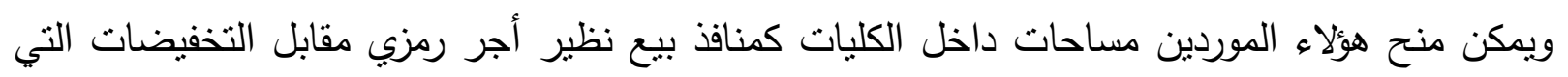

ستمنح للطلبة.

تنمبة موارد الطالب والجامعة

توفير فرص عمل داخل الجامعة والمدن الجامعية للطلبة مقابل أجر، مثل الاستعانه بهر كمساعدين

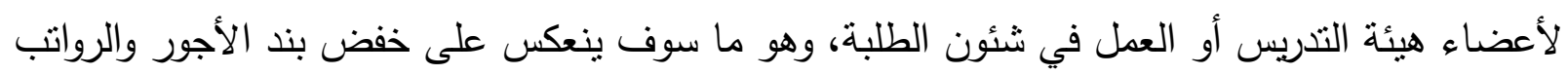
بالموازنه على المدى البعيد.

الإتفاق مع الموردين والمتعاملين مع الجامعة لتوفير فرص عمل للطلبة تراعي ظروفهم من حيث طبيعة العمل وأوقاته نظير بعض الإمنيازات لهؤلاء الموردين.

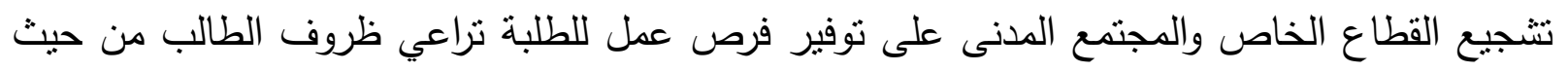

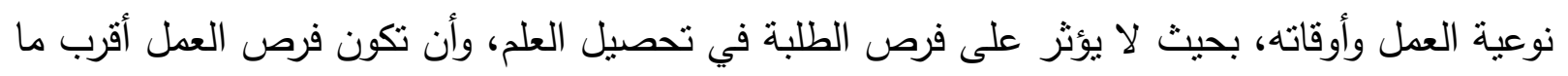
يكون لتدريب الطلبة وفقا لتخصصاتهم مما يساعدهم على التقوق العلمي.

التوسع في إنثاء وحدات إنتاجية أوخدمية أو تدريبية بالكليات حسب التخصص لتقديم خدمات بمقابل

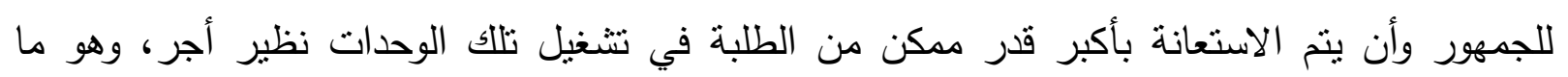

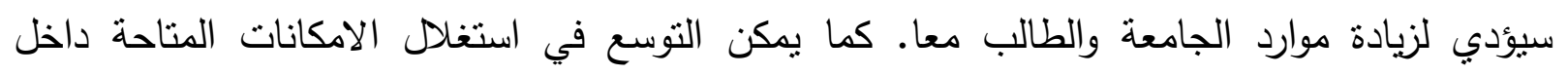

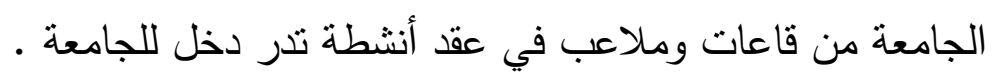

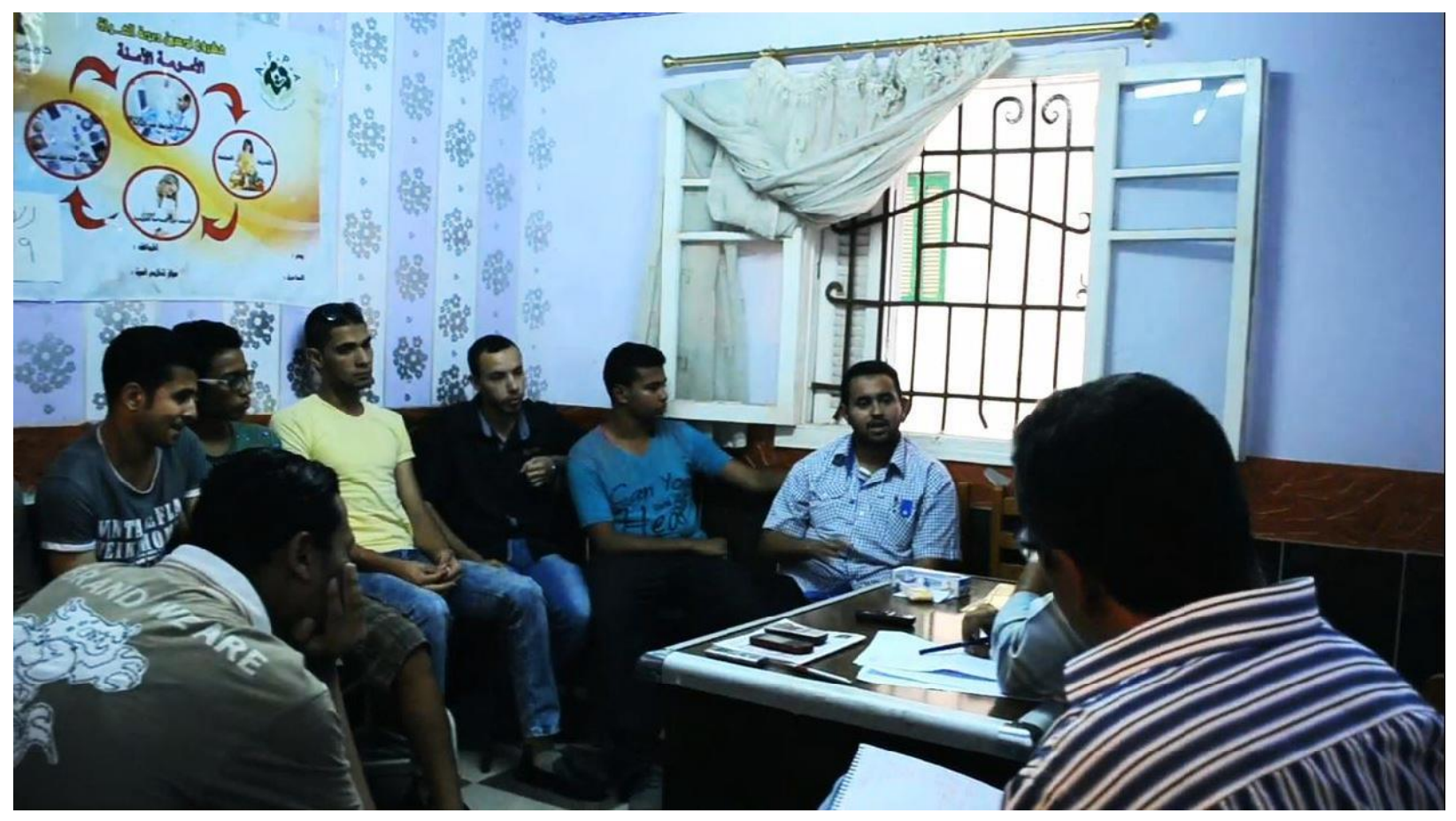




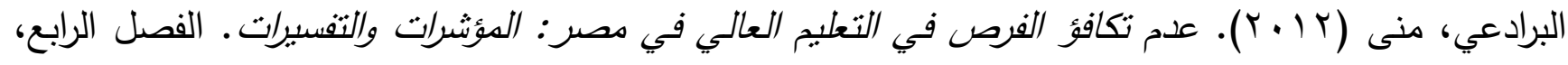

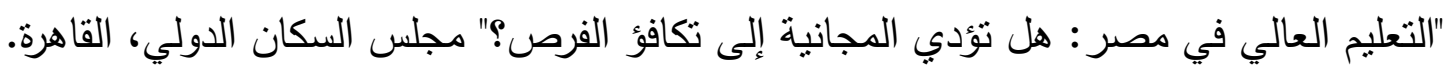

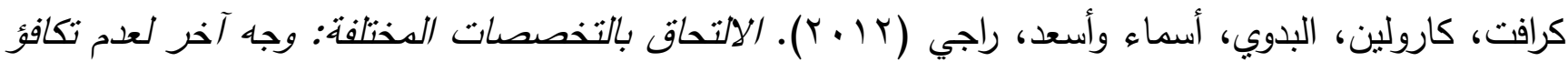

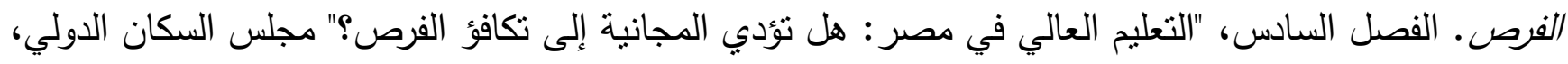

\section{شكر وتثقير}

تم اعداد هذه الورقة ضمن انشطة مشروع "العدالة والإنصاف في التعليم الجامعي" والذي قام بتتفيذه مجلس السكان الدولي بدعم من مؤسسة فورد بهدف توصيل نتائج البحوث إلى صانعي القرار والمسئولين بالجهات الدختلف

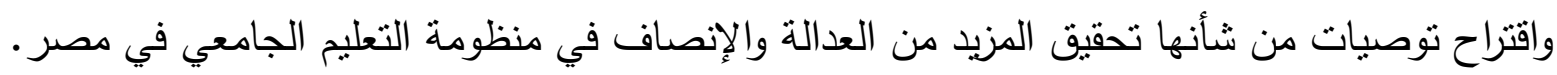

نتقدم بخالص الثكر والتقدير للإستاذة/ إلهام فطيم (إستتاري وخبير التتمية) ولفريق العمل بهذه الدراسة: الدكتورة/ نهلة عبد التواب والأستاذة/ سلمى أبو حسين والأستاذ/طارق طائ علم الدين والأستاذة/جيهان حسني.

كما نتقدم بالثكر للخبراء والاستشاريين وكذلك للطلبة وأولياء الأمور الذين أنثرا هذه الدراسة بأرائهم ومقترحاتهم.

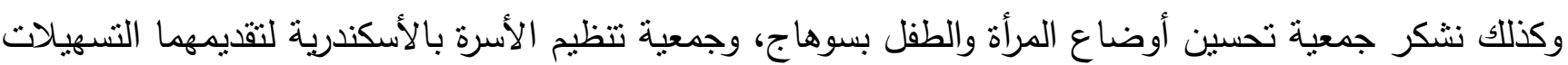

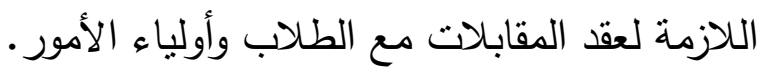

اخيراً ليس أخراً، نتقدم بجزيل الثكر والعرفان لمؤسسة فورد لدعمها المادي لأنشطة هذا المشروع الذي نأمل أن يسهم في تحسين منظومة التعليم العالي بما يحقق العدالة الإجتماعية وتكافؤ الفرص بين الثباب في مصر . 

(2)PULATION COUNCIL

Ideas. Evidence. Impact. 